\title{
Suprimir os fatos e privilegiar as sensações: a emergência da criança-autora em Clarice Lispector
}

\author{
Suppress facts and privilege sensations: \\ the child-author's emergency in Clarice Lispector
}

Fabio Scorsolini-Comin ${ }^{1}$

Recebido em: $13 / 05 / 2020$
Aprovado em: 04/06/2021
Publicado em: $30 / 07 / 2021$

RESUMO: A obra de Clarice Lispector (1920-1977) tem sido aclamada como uma das mais importantes da literatura nacional contemporânea. Em suas produções voltadas ao público infantil explora seu universo pessoal não apenas como mãe de duas crianças que the demandavam a criação de estórias, mas também recupera as próprias vivências infantis, quando se iniciou na arte da escrita. Em um primeiro momento, este estudo discute o surgimento da autora Clarice e o modo como essa autoria se relaciona à sua biografia, oferecendo material para a escrita ficcional. Posteriormente, exploram-se as possibilidades de empregar esses elementos no incentivo à leitura e à produção textual de jovens escritores a partir do relato de uma experiência interventiva no ensino fundamental. Como conclusão, destaca-se que as vivências infantis de Clarice foram fundamentais para o desenvolvimento de uma autora que, desde a tenra infância, explorou a escrita de suas sensações e experiências como forma de compreender o mundo e torná-lo inteligível. A partir do presente estudo, recomenda-se o incentivo à reflexão acerca da autoria com alunos do ensino fundamental, potencializando a emergência da criança-autora.

Palavras-chave: Autoria; Educação infantil; Literatura infantil; Clarice Lispector.

\begin{abstract}
Clarice Lispector's work (1920-1977) has been acclaimed as one of the most important in contemporary national literature. In her productions aimed at children, she explores her personal universe not only as the mother of two children who demanded the creation of stories, but also recovers her own childhood experiences, when she started in the art of writing. At first, this study discusses the emergence of the author Clarice and the way this authorship is related to her biography, offering material for fictional writing. Subsequently, the possibilities of using these elements to encourage reading and textual production by young writers are explored based on the report of an interventionist experience in elementary school. As a conclusion, it is emphasized that Clarice's childhood experiences were fundamental for the development of an author who, since early childhood, explored the writing of her sensations and experiences as a way of understanding the world and making it intelligible. Based on this study, it is recommended to encourage reflection on authorship with elementary school students, enhancing the assumption of the child-author.
\end{abstract}

Keywords: Authorship; Child education; Children's literature; Clarice Lispector.

1. Psicólogo, Mestre e Doutor em Psicologia pela Universidade de São Paulo. Docente do Departamento de Enfermagem Psiquiátrica e Ciências Humanas e do Programa de Enfermagem Psiquiátrica da Escola de Enfermagem de Ribeirão Preto, Universidade de São Paulo. ORCID: 0000-0001-6281-3371. E-mail: fabio.scorsolini@usp.br. 


\section{INTRODUÇÃO}

O estudo da autoria é um campo polifônico e polissêmico em que diferentes perspectivas convivem, chocam-se, sintetizam-se e produzem tensões que não possuem como objetivo a construção de um consenso. O filólogo Bakhtin (1979/1992) é um autor que tem contribuído para essa discussão por propor uma concepção de autoria que rejeita a existência de uma única perspectiva, a de um eu autocentrado capaz de produzir independentemente de seu contexto. Assim, suspende a noção bastante difundida da escrita como um produto solitário, de determinação exclusivamente individual, cerne da originalidade. A autoria, nessa perspectiva bakhtiniana, é uma produção coletiva que considera as múltiplas vozes que nos constituem continuamente e que circulam no espaço discursivo, de modo que seria impossível pensar o humano fora das relações que o ligam ao(s) outro(s), de modo isolado e individualizado (SCORSOLINI-COMIN, 2012). É por essa razão que, promovendo a releitura do conceito a partir de pressupostos histórico-culturais, põe em discussão a noção largamente difundida que associa a autoria a um esforço individual, isolado, a exercício introspectivo e criativo apartado de suas referências e registros em um meio social e histórico. Desse modo, ao trabalharmos com a autoria, é mister considerar não apenas o contexto de produção da obra, mas o contexto no qual o(a) autor(a) está imerso(a).

Uma das autoras mais reconhecidas da literatura brasileira contemporânea é Clarice Lispector. Nascida na Ucrânia, em 1920, foi naturalizada brasileira e faleceu em 1977. Seu nome verdadeiro era Haia Pinkhasovna Lispector. Haia, em hebraico, significa "vida". Recebeu o nome de Clarice ao se mudar para o Brasil. Morou em Maceió, Recife e Rio de Janeiro, e em países como Itália, Suíça e Estados Unidos. Atuando como jornalista e escritora, produziu uma obra composta por romances, contos e ensaios (FERREIRA, 1999; GOTLIB, 2009a; MOSER, 2017). Em 2020 foi comemorado o centenário de nascimento da autora, momento que permitiu a emergência de diversos estudos acerca de sua obra e também sobre a sua biografia.

A obra de Clarice também tem como uma de suas marcas o adensamento psíquico de suas personagens, em um investimento interno que supera seus condicionamentos sociais. Assim, o universo intrapsíquico de suas personagens emerge de modo evidente, o que promoveu a associação da autora ao chamado romance psicológico, voltado para o universo interno de suas personagens. Embora seus críticos e biógrafos considerem que Clarice tenha se aproximado de uma crítica mais social e política apenas em seu último e mais conhecido romance (FERREIRA, 1999; GOTLIB, 
2009a; MOSER, 2017), A hora da estrela, há que se considerar que a autora tem a sua narrativa de vida atravessada por diversos elementos sociais e culturais, como o fato de ter sido casada com um diplomata, de ter conhecido e convivido com estadistas, de ser judia e de ser uma das primeiras escritoras mulheres a alcançarem expressivo reconhecimento em um período literário dominado por homens no Brasil (MOSER, 2017). Esses eventos atravessaram a escrita de Clarice, de modo que sua produção, apesar de ser interpretada como essencialmente psicológica, intrapsíquica, não é construída a despeito de um universo de referências contextuais que a marcaram profundamente como mulher e, consequentemente, como autora.

Resgatando os apontamentos de Bakhtin (1979/1992), a autoria em Clarice também não pode ser apreendida como um produto único de suas experiências de vida ou de seu universo interno, mas, sobretudo, pelo modo como seu contexto de produção a influenciou e como as diferentes vozes sociais atravessam a sua escrita, ainda que, à primeira vista, as suas influências possam ser consideradas essencialmente individualistas, frutos de um mundo particular atribuído frequentemente aos escritores. Nesta acepção, portanto, por mais introspectivo que pareça ser o processo autoral, o que nos parece evidente quando analisamos a obra de Clarice de modo associado à sua biografia, devemos compreender que esses elementos, na escrita, costuram-se a um espaço discursivo coletivo que nem sempre é passível de análise (POJAR; SCORSOLINI-COMIN, 2020; SCORSOLINI-COMIN; SANTOS, 2010; SCORSOLINI-COMIN; SILVA, 2018a).

A obra de Clarice é totalmente atravessada por suas experiências pessoais que ora privilegiam seu posicionamento como mãe, mulher, esposa e jornalista, ora como a criança que fora, sobretudo quando residiu no nordeste do país. Ao optar por uma escrita pessoal e que reflete a si mesma acaba se recusando às trajetórias de muitos escritores clássicos de sua época, sobretudo os regionalistas, como Jorge Amado e Guimarães Rosa, por exemplo. A sua aparente recusa em evidenciar ou se aprofundar nos aspectos contextuais e nos dramas sociais de suas personagens, com exceção de Macabéa, não significa, em momento algum, uma escrita apartada de sua realidade. Talvez essa característica, em Clarice, torne ainda mais complexa a investigação acerca da construção do seu processo autoral.

A investigação dessa autoria parte, em sua maioria, de suas obras consideradas clássicas e mais reconhecidas pelo público e também pelos críticos, como $A$ hora da estrela (1977), Perto do coração selvagem (1943) e A paixão segundo G. H. (1964). De menor monta é o interesse pela sua prosa voltada ao público infantil. Os livros que compõem a 
literatura infantil de Clarice Lispector são O mistério do coelho pensante (1967), A mulher que matou os peixes (1968), A vida íntima de Laura (1974), Quase de verdade (1978) e Como nasceram as estrelas (1987), este último com lendas brasileiras. Do mesmo modo que se observam as experiências pessoais de Clarice atravessando as suas narrativas e personagens adultos, também nessa escrita voltada às crianças observa-se a emergência de posicionamentos tais como os da mãe e também da criança-Clarice, de modo a problematizar a costura da sua vida pessoal - e das suas percepções sobre esse viver em sua construção como autora para crianças (SCORSOLINI-COMIN; ALVES, 2018b; SCORSOLINI-COMIN, 2019).

Uma característica comum dos personagens desses livros infantis é o protagonismo dos animais, inclusive assumindo posições como as de narrador, como o cachorro Ulisses de Quase de verdade. Ao se aproximar dos animais, Clarice tenta resgatar uma vida mais instintiva e básica que, segundo ela, seria mais acessível ao público infantil (DINIS, 2003). Clarice não considera o mundo humano superior ao mundo animal, pelo contrário, apresenta os instintos básicos como importantes de serem resgatados pelo humano, buscando maior conexão com a natureza. Esse resgate é descrito por Gotlib (2009a) em termos de uma força selvagem.

Nessas obras, são frequentes as menções de Clarice às suas experiências enquanto criança e, sobretudo ao início da sua construção como autora, ainda na infância, quando "descobre" o ofício de escritora e o elege como uma possibilidade em sua vida (SCORSOLINI-COMIN, 2019), ainda que tenha, formalmente, tentado a carreira de advogada ao cursar a faculdade de Direito, no Rio de Janeiro (GOTLIB, 2009a; MOSER, 2017). A partir desse panorama, em um primeiro momento, este estudo discutirá o surgimento da autora Clarice e o modo como essa autoria se relaciona à sua biografia enquanto material para a escrita ficcional. Posteriormente, apresentaremos o relato de uma experiência realizada no ensino fundamental a partir de sua obra voltada ao público infantil.

\section{Suprimir os fatos e privilegiar as sensações: Clarice-criança-autora}

A escritora Clarice tem sua origem na Clarice menina, rodeada por brincadeiras, leituras, escritos e por um mundo interno depurado ao longo de toda a sua obra, o que também inclui as suas relações familiares e o contato com seus amigos da época. Como destacado por Gotlib (2009a), o universo criativo da menina Clarice remonta à sua relação com o seu meio, notadamente a cidade do Recife:

Mas o brincar ou inventar é também uma aventura, um estado de risco, que a menina de então praticava na cidade de Recife, recortada por rios,

Revista do SELL, Uberaba/MG (online) - V. 10 n. 1, p. 135-154, jan. /jun. - 2021. 
recheada de inúmeras ilhas, antes dos sucessivos aterros que foram descaracterizando a chamada 'Veneza brasileira (p. 68).

Esse universo da cidade é retratado ou capturado por Clarice em seus contos, especificamente em Felicidade clandestina (LISPECTOR, 1998) e Cem anos de perdão (LISPECTOR, 1998). A menina Clarice aparece, desse modo, como personagem que não abandona a Clarice adulta, revelando que o processo autoral não pode ser datado ou automatizado, como se uma determinada fosse fruto ou uma influência exclusiva de uma dada experiência atual. O resgate das experiências pessoais, em Clarice, pode ser compreendido como algo complexo e denso, ora priorizando um diálogo que parece ligar a Clarice criança e a Clarice adulta, ora distanciando-as, como se fossem pessoas distintas, embora unidas em um mesmo continuum. O universo da leitura e da escrita, ainda na infância, costura de modo determinante a sua experiência como escritora na vida adulta, promovendo ressonâncias na emergência da autora que posteriormente conhecemos em Perto do coração selvagem, seu romance de estreia:

Depois, quando eu aprendi a ler e a escrever, eu devorava os livros! Eu pensava, olha que coisa! Eu pensava que livro é como árvore, é como bicho: coisa que nasce! Não descobria que era um autor! Lá pelas tantas, eu descobri que era um autor. Aí disse: 'Eu também quero'. ${ }^{1}$

A descoberta do ser-autor, segundo esse relato, provoca em Clarice uma rápida identificação, promovendo o seu desejo de também ser escritora. Assim, o desejo de ser/tornar-se escritora remonta à sua infância, quando já encaminhava seus primeiros textos para a seção infantil de um jornal do Recife, o Diário de Pernambuco (SCORSOLINICOMIN; SILVA, 2018a). Mas Clarice nunca teve um texto selecionado para publicação neste jornal, fato este comentado por ela, anos mais tarde e frequentemente evocado por seus biógrafos (GOTLIB, 2009a; MOSER, 2017):

Nunca ganhei nada. Depois de muito pensar encontrei o porquê: todas as histórias vencedoras relatavam fatos verdadeiros. As minhas somente continham sensações e emoções vividas por personagens fictícias. ${ }^{2}$

As outras crianças eram publicadas e eu não. Logo compreendi por que: elas contavam histórias, uma anedota, acontecimentos. Ao passo que eu relatava sensações... coisas vagas. Mas sou teimosa e não fiz ao longo da minha vida senão perseverar na mesma trilha, suprimir os fatos e privilegiar as sensações. Com o risco de não ser publicada. ${ }^{3}$

A escrita para a criança ocupa um lugar semelhante ao da brincadeira. Donald Winnicott (2017) foi um psicanalista inglês que explorou de modo bastante aprofundado

\footnotetext{
${ }^{1}$ Entrevista concedida por Clarice Lispector em 20 de outubro de 1976 e recuperada por Gotlib, 2009a, p. 81.

2 Entrevista concedida a Leo Gilson Ribeiro em 1969 e recuperada por Gotlib, 2009a, p. 82.

${ }^{3}$ Entrevista concedida a Maryvonne Lapouge e Clelia Pisa e recuperada por Gotlib, 2009a, p. 83.
}

Revista do SELL, Uberaba/MG (online) - V. 10 n. 1, p. 135-154, jan. /jun. - 2021. 


\section{SCORSOLINI-COMIN, F.}

esse universo infantil e o modo como a brincadeira possa estar associada não apenas ao que contemporaneamente compreendemos por desenvolvimento cognitivo e de estimulação de uma sensorialidade, mas à construção de um mundo interno, experiencial, que permite à criança lidar com as próprias emoções. Assim como ocorre no desenho e no grafismo, em que a criança pode expressar o seu mundo interno e trabalhar com as suas emoções, a escrita também permitiria à criança esse lugar expressivo e necessário ao amadurecimento emocional. Assim, destaca-se que a escrita, na infância, pode ocupar um lugar importante, permitindo não apenas a construção de um canal de comunicação e expressão com o mundo e seu entorno, mas também de elaboração de experiências, sentimentos e emoções que permitem à criança, ao longo do tempo, amadurecer internamente e integrar-se.

Esse argumento nos permite considerar que a escrita, na Clarice menina, ocuparia uma função semelhante à do desenho e da expressão artística e lúdica segundo as proposições winnicottianas, permitindo, inclusive, trabalhar com a agressividade, por exemplo, o que retoma a ideia das emoções mais básicas ligadas ao mundo animal (SCORSOLINI-COMIN, 2019; SCORSOLINI-COMIN; SILVA, 2018a; 2018b). A escrita, nessa aproximação, é um modo de comunicação, de expressão e também de produção de vivências. A escrita é uma possibilidade de criação do mundo e no mundo, uma possibilidade de integração. A menina Clarice corporifica esses elementos, buscando expressar, em seus escritos infantis, as suas sensações relacionadas tanto à sua percepção sobre o mundo exterior, concreto, como em relação ao seu mundo interno. Essa expressão, obviamente, não permanece apenas nas suas produções enquanto criança, mas permeia, sobretudo ao escrever para crianças, a sua escrita enquanto adulta.

A partir dessas considerações sobre a biografia de Clarice podemos problematizar a emergência da autoria na infância da autora e sobre a infância em sua bibliografia (DINIS, 2003; SCORSOLINI-COMIN, 2019). Ao aproximarmos essas considerações da educação voltada às crianças, podemos destacar que um itinerário semelhante possa ser construído na escola. Ao narrarem as suas experiências em cartas, bilhetes, poesias e contos, por exemplo, as crianças podem refletir sobre suas questões internas, buscando não apenas explicações para elas, mas também um modo de se colocarem no mundo.

No relato de experiência que será apresentado no presente estudo, desenvolvido no contexto do Ensino Fundamental, as crianças colocaram-se a partir do ponto de vista do escritor como produtor de enredos e de realidades, o que não se dá a partir de uma perspectiva apenas cognitiva e de domínio da linguagem, mas de diálogo com o próprio 
mundo interno. Os estudantes puderam misturar experiências pessoais, ainda tenras, com ficções criadas a partir dos convites do projeto. Ao fomentar esse processo, a escola cumpre não apenas seu papel oficial e atinente ao currículo, ligado a uma disciplina ou ao processo formal de escolarização e de socialização, mas endereça convites para que esse desenvolvimento emocional continue ao longo de todo o crescimento da criança.

Mas, para estabelecermos um diálogo com esse universo da criança, retomemos a obra de Clarice voltada ao público infantil. O livro A mulher que matou os peixes (1999b) é a narrativa não de um crime em si, cometido pela Clarice-autora-mãe, mas da tentativa de se redimir por ter negligenciado cuidado aos peixes dos filhos - e também, de algum modo, aos próprios filhos, haja vista que Clarice trabalhava bastante em casa, ora dedicando-se ao ofício de escritora, ora à profissão de jornalista, o que diminuía o tempo em que podia estar integralmente com os filhos. É um pedido de desculpas de uma mulher que se dividia entre os cuidados com a família e o seu ofício da escrita.

Essa mulher que matou os peixes infelizmente sou eu. Mas juro a você que foi sem querer. Logo eu! que não tenho coragem de matar uma coisa viva! (LISPECTOR, 1999b).

Ao se posicionar como mãe que precisa atuar em diferentes frentes, profissionais, pessoais, ligadas à família e aos filhos, a escritora mostra-se próxima dos leitores, sendo, para além da escrita, uma mãe aflita que pretende explicar o mundo aos filhos. Ela também pretende explicar isso às crianças que a leem, por vezes se colocando na posição dos pais atarefados e sempre preocupados com o tempo que deixam de passar com os filhos, por vezes se colocando na posição de seus pequenos leitores, ávidos por explicações sobre o mundo e o funcionamento das coisas.

A escrita de Clarice dialoga diretamente com os seus leitores. Ao longo de todo o livro ela interpela o jovem leitor: você me perdoa? Você pode me perdoar? Você percebe que eu não tive culpa? Pelos dados que serão apresentados ao longo deste estudo, as crianças, ao lerem essa obra, também dialogam com Clarice, mobilizando-se ora na tentativa de perdoar a autora-mãe-ocupada, ora condenando-a pelo ato de negligência. $O$ livro promove um vai-e-vem nas explicações e nos pedidos de reconsideração, o que também permite, à criança, ir-e-vir nas suas justificativas e também no modo como pode "julgar" essa mãe-escritora. Para além dos aspectos relacionados à construção da moralidade nesta etapa do desenvolvimento, as crianças, então, aproximam-se da autora, da mãe, do ser humano, de Clarice. A escritora não é mais uma "criminosa", uma mãe negligente. O livro não é mais sobre crimes. $O$ livro é sobre a vida e todos podem ocupar a posição de autores das próprias experiências (SCORSOLINI-COMIN, 2018a). 
Assim, a escritora Clarice passa a ser apenas uma Clarice próxima dos alunos, cujas experiências se misturam, dialogam entre si, permitindo a identificação da criança com Clarice e, consequentemente, da criança com a autora. Ao identificar-se com a autora, legitima-se, também, o processo de construção da própria autoria. Esse é o argumento principal que orientou a proposta interventiva que será descrita a seguir. $O$ relato de experiência que será apresentado no presente estudo retrata um projeto desenvolvido com alunos do quinto ano do Ensino Fundamental de um colégio privado localizado no interior do Estado de São Paulo.

Essa Clarice essencialmente humana e próxima, concreta e real, passa a habitar as estórias e as histórias desses estudantes. A literatura, igualmente, deixa de ser um elemento distante e elitizado, voltado a poucos, e passa a ser algo cotidiano, que pode ser acessado e construído por todos. A autoria, assim, deixa de ser algo que apenas algumas pessoas podem desenvolver por possuírem características específicas e passa a ser produzida em sala de aula, semanalmente e a partir dos convites da agora, próxima, Clarice.

Um dos elementos que contribuem para esse processo é o modo como Clarice evoca em seus textos os personagens animais. Muitos dos bichos e personagens desses livros infantis realmente existiram na biografia de Clarice, a exemplo dos peixes de $A$ mulher que matou os peixes. Clarice era, pois, a mulher que havia matado os peixes, como anunciado no título da obra. Ao nos trazer para tantas histórias e estórias carregadas de humanidade, Clarice opera um sentido oposto ao do seu livro infantil sobre a morte dos peixes: segundo Scorsolini-Comin e Silva (2018a), ela não mais mata os peixes, mas, pelo contrário, os salva. Quando narra a morte dos dois peixinhos vermelhos dos filhos, Clarice quer salvar seus leitores - sobretudo as crianças que a leem, como se arrebatasse seus leitores para uma experiência estética e existencial que só a literatura permite (SCORSOLINI-COMIN; SILVA, 2018b).

A partir do exposto, exploraremos, a seguir, as possibilidades de empregar esses elementos no incentivo à leitura e à produção textual de jovens escritores a partir do relato de uma experiência produzida no Ensino Fundamental. Com isso, apresentamos uma possibilidade de abordagem do processo de autoria com crianças, incentivando não apenas uma formação tecnicista relacionada à linguagem e ao texto, fundamentais à autoria, mas a um percurso constitutivo que explora o universo interno da criança e o seu amadurecimento ao longo do tempo. 


\section{A narrativa de uma intervenção no Ensino Fundamental}

A proposta do projeto de cultura e extensão universitária narrado neste estudo surgiu da interlocução e da necessidade de diálogo entre a educação básica e a universidade pública, fomentando discussões importantes na formação das crianças, fundamentalmente aquelas que colocam em destaque o modo como a literatura revela valores, afetos e construções sociais importantes no manejo de comportamentos e também no amadurecimento das crianças. O diálogo a partir da literatura teve como objetivo permitir aos estudantes empreenderem reflexões aprofundadas sobre o mundo, sua existência e aspectos do cotidiano interpessoal (SCORSOLINI-COMIN; SILVA, 2018a).

O chamado "Projeto Clarice" teve por objetivo aproximar os alunos do ensino fundamental da literatura produzida por Clarice Lispector voltada especificamente ao público infantil. Além desse objetivo central, buscou-se apresentar a autora Clarice Lispector em termos de sua biografia pessoal e formação como escritora, discutindo as aproximações entre autora e obra. Esses objetivos foram operacionalizados a partir das seguintes ações: (a) realização de rodas de contação de histórias a partir da literatura infantil produzida por Clarice Lispector; (b) criação de espaços de reflexão com os alunos acerca das obras infantis de Clarice Lispector; (c) incentivo à produção textual dos alunos, tendo como disparador as obras infantis de Clarice Lispector; (d) desenvolvimento de atividades artísticas e culturais a partir da biografia de Clarice Lispector e de suas obras ficcionais voltadas ao público infantil (SCORSOLINI-COMIN; SILVA, 2018b).

Este projeto de cultura e extensão universitária foi realizado ao longo do segundo semestre de 2018, em uma parceria com uma universidade pública do interior do estado de São Paulo. O projeto teve a coordenação geral de um professor universitário com formação em Psicologia. Na escola, o projeto foi coordenado por um professor com formação em História. Participaram os alunos regularmente matriculados no quinto ano do Ensino Fundamental deste colégio.

A cada semana o projeto era desenvolvido em três momentos. A primeira parte era composta pela leitura do livro com os alunos. Na segunda havia uma roda de conversa com os alunos, priorizando os aspectos psicológicos e filosóficos disparados por cada livro, como família, amizade, diversidade, generosidade, solidariedade, sociedade, descoberta e finitude, por exemplo (SCORSOLINI-COMIN; SILVA, 2018a). O terceiro momento envolvia a produção de textos por parte dos alunos, tendo como referência o livro trabalhado naquela semana e os temas discutidos na roda de conversa. A cada semana os alunos produziram um tipo diferente de texto a partir da história contada - por exemplo: conto, carta e bilhete.

Revista do SELL, Uberaba/MG (online) - V. 10 n. 1, p. 135-154, jan. /jun. - 2021. 
Em todos os encontros, a professora de referência da turma esteve presente, participando também da organização das atividades.

No início do projeto, os alunos entraram em contato com a biografia da autora, por meio de uma aula com diversas fotos e ilustrações (GOTLIB, 2009b). Para essa apresentação foi empregada a biografia da autora, escrita por Gotlib (2009a). A biografia escrita por Moser (2017) também foi utilizada como referência. Foram mencionados fatos importantes na história de vida da autora, o que os auxiliou a compreender muitas das narrativas apresentadas posteriormente, como a ligação de Clarice com os animais e suas experiências na infância.

No primeiro encontro foram lidos dois contos, Felicidade clandestina e Cem anos de perdão. Ambos os textos trazem narrativas sobre crianças e o universo de fantasia que circunda essa fase do desenvolvimento. Os alunos fizeram discussões e posteriores atividades de reescrita, buscando aproximarem-se do estilo de escrita da autora. Foi o primeiro contato deles com a Clarice menina e suas experiências reais e emocionais.

Posteriormente, realizaram oficinas de escrita com máquinas de escrever, em clara referência aos ofícios de jornalista e escritora vivenciados por Clarice. Nessa ocasião os alunos aprenderam alguns princípios básicos de datilografia e puderam comparar esse processo com os mais atuais e vivenciados por eles cotidianamente. Foram discutidos os avanços tecnológicos e como as novas tecnologias de informação e de comunicação são importantes no processo de ensino-aprendizagem. Ao longo das demais semanas, as oficinas de escrita trouxeram estruturas textuais específicas, como bilhetes, cartas, crônicas e contos. Todos esses processos foram devidamente registrados e os textos produzidos compuseram um livro (SCORSOLINI-COMIN; SILVA, 2018b). O processo autoral, de caráter individual e também em diálogo com o mundo e a coletividade, foi priorizado como forma de acesso a experiências e depuração de vivências emocionais. A seguir, serão apresentadas as sequências trabalhadas com as crianças a partir dos livros infantis de Clarice e de seus contos.

\section{Primeiro encontro}

O conto Felicidade clandestina (LISPECTOR, 1998), presente em um livro homônimo da autora, narra a epopeia de uma menina com o livro que sua amiga jamais the emprestava. Ao conseguir o livro emprestado por tempo indeterminado, por intermédio da mãe de sua amiga, a menina vivencia momentos de puro êxtase junto do livro, em um processo que também metaforiza a operação psíquica que permite à futura leitora 
equacionar o saber intelectual ao universo sensorial que abre passagem para a fruição estética (SCORSOLINI-COMIN, 2019).

Neste conto, a autora rememora as suas experiências quando criança, em situação semelhante, também ocorrida no Recife (MOSER, 2017). A partir de então a biografia da autora foi apresentada à turma. Essa foi uma preocupação inicial do projeto no sentido de que as crianças pudessem, de fato, não apenas conhecer a autora, mas também os desdobramentos de suas experiências pessoais em sua escrita, tanto nos enredos abordados quanto em seu estilo de escrita. A biografia de Clarice suscitou diversos questionamentos. E por que não endereçar essas perguntas à própria autora, por exemplo? Uma das formas possíveis de fazer isso foi usando uma comunicação breve: o bilhete.

Neste encontro os alunos produziram bilhetes endereçados à Clarice Lispector. Após conhecerem a biografia da autora e lerem os contos Felicidade clandestina e Cem anos de perdão, os alunos participaram de uma oficina de escrita com máquinas de escrever. Os alunos trouxeram suas máquinas de casa, a partir de um pedido feito aos pais e responsáveis por meio de bilhetes, e estas foram usadas para aprender, inicialmente, algumas técnicas básicas de datilografia. Alguns professores também trouxeram máquinas para emprestá-las ao projeto. Antes da realização da atividade, as máquinas foram limpas e verificadas para o uso. Depois disso puderam escrever os próprios textos.

Trabalhar com as máquinas de escrever foi um grande processo de aprendizado. Alguns dos alunos nunca tinham manuseado uma máquina. Os alunos conversaram, paralelamente, sobre tecnologias, formas de comunicação, acesso à informação, veiculação de notícias, além do ofício do jornalista e do escritor. Embora com os estranhamentos iniciais já esperados, a atividade foi considerada exitosa a partir da avaliação dos alunos: "Clarice escrevia com uma máquina dessas?". "Nossa, era mais difícil escrever do que hoje?" ou "O bom dessa máquina é que ela já imprime!". Comentários como esses foram muito expressivos durante a atividade. A fotobiografia da autora (GOTLIB, 2009b) traz diversos registros de Clarice à máquina, o que foi salientado pelos alunos.

Esses textos tinham como objetivo fazer uma aproximação com a autora, trazendo percepções iniciais a partir da leitura dos seus contos e do contato com a sua biografia. Muitos dos alunos também optaram por comentar acerca dos contos que haviam lido e também se apresentarem para Clarice (SCORSOLINI-COMIN; SILVA, 2018a; 2018b). Aqui aconteceu um primeiro processo que deve ser destacado no projeto: a identificação das crianças com a Clarice menina, encantada com a cidade, que roubava rosas e pitangas, 
que tinha o seu mundo particular. Essa aproximação revela a marca atemporal dos seus escritos e de como o seu modo de se comunicar com crianças ainda continua atual, ainda que muitas mudanças tenham se operado em nossa sociedade. Além desses aspectos, a proximidade entre as crianças e Clarice possui como característica a possibilidade de capturar esses jovens leitores e escritores para um universo no qual autora e leitores se entendem e se reconhecem.

\section{Segundo encontro}

Neste encontro foi trabalhada a obra $O$ mistério do coelho pensante. Este foi o primeiro livro infantil escrito por Clarice $^{4}$ e produzido a pedido de um dos seus filhos, Paulo. Clarice tinha dois filhos, Paulo e Pedro. Originalmente escrito em inglês, foi lido nesse idioma aos filhos, uma vez que Clarice e família residiam no exterior. Só depois de muito tempo ele foi traduzido e publicado para crianças no Brasil (GOTLIB, 2009a), quando um editor perguntou à autora se ela poderia escrever algo voltado a esse público (MOSER, 2017). Clarice presta aqui uma homenagem aos coelhos que residiram com a família e afirma que as crianças só vão gostar do livro se se simpatizarem com esses bichos. A temática dos bichos, presente em todos os seus livros infantis (DINIS, 2003), consagra a afirmação de que os animais são "uma das formas acessíveis de gente" 5 .

O livro se baseia em um fato verídico e de uma curiosidade que tomava toda a família: como o coelho, chamado Joãozinho, conseguia sair de uma gaiola que estava fechada? Há um elemento a mais: Joãozinho podia pensar! Ao mexer o seu nariz ele podia pensar. Que tipo de coisa pode pensar um coelho?

O desafio nessa atividade era que os alunos pudessem construir explicações para o mistério, assim como Clarice fez ao longo de todo o livro. Foram trabalhados com os alunos aspectos como a redação de hipóteses, a verificação de hipóteses, a possibilidade de construção de experimentos e testes para verificá-las, as observações, os registros das observações e a própria atividade do pesquisador que pode ser narrada em termos da tentativa de explicar os fenômenos que fazem parte da nossa vida. Basicamente, foi trabalhado com os alunos que o pesquisador é alguém que tenta explicar o mundo que o cerca. Neste encontro, apresentou-se um pouco como esse processo é realizado nas pesquisas na Universidade, como, por exemplo, no desenvolvimento de medicamentos e

\footnotetext{
${ }^{4}$ Segundo Gotlib (2009a), a primeira história infantil escrita por Clarice foi em uma carta para sua sobrinha Márcia, em 26 de novembro de 1946. Era a historieta do Menino Sá, que narra a história de um menino que come uma abóbora dentro da qual há um outro menino. Essa história não chegou a se tornar um livro.

${ }^{5}$ Afirmação presente em "A explicação inútil”, do livro "A Legião Estrangeira". Recuperado de Gotlib (2009a, p. 332).
}

Revista do SELL, Uberaba/MG (online) - V. 10 n. 1, p. 135-154, jan. /jun. - 2021. 
vacinas que são importantes para a saúde de todos. Obviamente que a escrita dessas hipóteses, no espaço narrativo criado pelos alunos no encontro, não precisa envolver apenas a realidade e aquilo que podia ser comprovado por eles. Assim, foi trabalhado o elemento da fantasia e da narrativa fantástica como uma possibilidade, na literatura, de solucionar alguns conflitos e dificuldades que poderiam não se aportar no real.

\section{Terceiro e quarto encontros}

Nestes dois encontros, foi trabalhado o livro $A$ mulher que matou os peixes. O livro narra a história de um "crime" que realmente aconteceu na vida de Clarice Lispector. Ela foi incumbida de cuidar de dois peixes vermelhos dos filhos, os chamados "vermelhinhos". Clarice esqueceu-se de dar comida aos peixes e eles morreram, o que entristeceu muito os filhos. A isso ela deu o nome de distração - por estar distraída, esquecera-se de alimentar os peixes. A narrativa da autora busca, basicamente, redimir-se desse crime, 0 que se dá desde o início:

Se eu tivesse culpa, eu confessava a vocês, porque não minto para menino ou menina. Só minto às vezes para certo tipo de gente grande porque é o único jeito. Tem gente grande que é tão chata! Vocês não acham? Elas nem compreendem a alma de uma criança. Criança nunca é chata. (LISPECTOR, 2010, p. 22).

A autora aqui se apresenta como uma mãe que se preocupa com os filhos e que quer dizer que não é nenhuma criminosa. Para tanto, a autora recorre a diversas passagens de experiências próprias com bichos, a fim de que o leitor entenda que Clarice não era uma pessoa má e que não gostava de animais, mas sim alguém que podia errar, como todas as pessoas. A narrativa do seu erro emerge como uma busca por perdão. Clarice parece pedir perdão não apenas aos filhos, mas, sobretudo, aos leitores. No projeto, ao lerem sobre o "crime", muitos alunos inicialmente mostraram-se revoltados e desapontados com Clarice. A autora conta todos os detalhes do crime e busca no leitor um alívio para essa experiência dolorosa. O livro conta histórias de diversos outros bichos, sendo que muitos deles fizeram parte da vida da autora desde a sua infância (SCORSOLINI-COMIN; SILVA, 2018a).

Um aspecto importante disparado pela leitura desse livro refere-se ao modo como a narrativa mobiliza nas crianças um determinado posicionamento acerca de um comportamento adulto que, de algum modo, não considera as necessidades ou o universo da criança. Clarice se coloca, pois, em uma posição de quem quer ser julgada para expurgar a própria culpa, mas de quem também quer ser "absolvida" por quem, de fato, interessa: o leitor. Clarice frequentemente era questionada pelas crianças sobre as suas obras infantis. Em uma entrevista de 1976, relatou que:

Revista do SELL, Uberaba/MG (online) - V. 10 n. 1, p. 135-154, jan. /jun. - 2021. 
Hoje eu fui entrevistada por quatro menininhas de onze anos do Santo Inácio, com fotografia, perguntas e perguntas e perguntas... por causa da Mulher que matou os peixes. E se era verdade que eu gostava de bicho. Eu disse: - Eu também sou bicho! Mas depois, depois, elas saíram, me deixaram muito cansada. (GOTLIB, 2009a, p. 478).

Após a leitura do livro, os alunos foram convidados a pensar nas histórias dos próprios bichos de estimação (ou de bichos imaginários, sobretudo para quem não tinha algum animal doméstico) e escreverem contos cujos personagens fossem esses animais, fictícios ou reais. Foram explicados os elementos que compõem o conto, como tempo, espaço, personagens, enredo e clímax, retomando alguns dos conhecimentos que eles já haviam adquirido previamente nas aulas de Língua Portuguesa. Também foi mostrado como Clarice ficou famosa escrevendo contos sobre diversos temas em jornais e revistas, sendo que alguns de seus livros são coletâneas de contos, como o clássico Laços de família, publicado originalmente em 1960, quando a autora se separa do marido e volta a viver no Brasil (MOSER, 2017).

\section{Quinto encontro}

Neste encontro, foi trabalhado o livro A vida íntima de Laura. O estranhamento inicial com esse livro dá-se em função de quem é a personagem principal da narrativa: Laura é uma galinha. À época, os críticos especulavam quem seria a Laura do próximo livro de Clarice (GOTLIB, 2009a; MOSER, 2017). De alguma forma, o fato de se tratar de uma galinha acaba gerando tanto um movimento de frustração no leitor (esperava-se uma humana como protagonista de um dos livros dessa importante escritora) quanto de curiosidade: o que teria de íntimo na história de uma galinha? A vida pacata da galinha acaba despertando diversos questionamentos. Esse estranhamento, no entanto, é mais circunscrito ao adulto, provavelmente já acostumado com a escrita de Clarice voltada a personagens humanos. Com as crianças, no projeto, esse estranhamento é diluído e aceito sem reservas, haja vista que os animais são frequentemente os personagens dos livros com os quais possuem contato. A humanidade da galinha emerge como ponto alto do livro. Clarice nos explica dessa forma:

Vou logo explicando o que quer dizer 'vida íntima'. É assim: vida íntima quer dizer que a gente não deve contar a todo mundo o que se passa na casa da gente. São coisas que não se pode dizer a qualquer pessoa. (LISPECTOR, 1999c, p. 7).

Os alunos puderam refletir, então, sobre o que é intimidade. Nessa conversa também emergiu a questão do que é segredo, se os segredos devem ser contados ou não, de que alguns segredos não podem ser escondidos dos pais, entre diversos outros pontos

Revista do SELL, Uberaba/MG (online) - V. 10 n. 1, p. 135-154, jan. /jun. - 2021. 
(SCORSOLINI-COMIN; SILVA, 2018a). Os alunos conversaram sobre o fato de que a intimidade é algo do próprio indivíduo e que deve ser preservado, cuidado e protegido. Muitas reflexões importantes sobre intimidade, sigilo e proteção em relação ao próprio corpo foram potencializadas nesse encontro a partir das dúvidas das crianças. O exercício de escrita proposto nesse encontro foi explorar algo do universo da intimidade de cada um que pudesse ser compartilhado. Assim, os alunos descreveram aspectos pessoais que consideravam íntimos, mas que não os expunham e que, então, podiam compor uma narrativa a ser compartilhada com a turma. Pequenos "segredos" ou aspectos íntimos que nunca haviam contado para ninguém também foram narrados, retomando também o estilo das revelações tecidas por Clarice em Cem anos de perdão, o que foi trabalhado no primeiro encontro do projeto.

\section{Sexto encontro}

Neste encontro foi trabalhado o livro Quase de verdade. Esta narrativa não é mais conduzida por Clarice, mas pelo cachorro Ulisses, considerado por ela o seu fiel escudeiro. A primeira inovação, no livro, portanto, é a escolha do seu narrador e o modo como o mesmo dialoga com a autora, o tempo todo revelada ao leitor como quem está interpretando a narrativa do cão:

- Engole-se ou não se engole o caroço?

Você, criança, pergunte isso à gente grande. Enquanto isso, eu digo:

- Au, au, au!

E Clarice entende que eu quero dizer:

- Até logo, criança! Engole-se ou não se engole o caroço?

Eis a questão. (LISPECTOR, 2010, p. 65).

Clarice, aqui, adquire a função de intérprete daquilo que o cão dita-lhe, ou melhor, late: "Eu fico latindo para Clarice e ela - que entende o significado de meus latidos - escreve o que eu lhe conto" (LISPECTOR, 2010, p. 51). O chamado "cão-narrador" (GOTLIB, 2009a, p. 557) traduz uma força selvagem, instintiva e com a qual a autora se identifica, retomando também os apontamentos de Dinis (2003) e de Moser (2017). Ulisses cumpre essa função no livro, sendo que a história de vida do cachorro também atravessa a vida autora, o que é retratado por Moser (2017) ao tratar de um episódio triste no qual Clarice teve um acidente doméstico, sofrendo queimaduras que seriam por muitos anos rememoradas pela autora como fonte de sofrimento.

No livro trabalhado no sexto encontro, oscilando entre a realidade e a fantasia, Ulisses traz à baila uma história de exploração e de organização social. Em poucas palavras, um coletivo de galinhas e galos se organiza contra a opressão e a tirania de uma 


\section{SCORSOLINI-COMIN, F.}

figueira. Na discussão com os alunos emergiram aspectos como cobiça, ciúme, inveja e competição. Nesse encontro, acompanhado pelo professor de História, os alunos também puderam fazer alguns paralelos com processos sociais e políticos com os quais eles entrariam em contato na disciplina ao longo do Ensino Fundamental.

Ao final do projeto, foi realizada uma avaliação com a turma. Essa avaliação deuse no modelo grupal, buscando conhecer o modo como puderam se desenvolver nos encontros. Assim, finalizada a leitura das obras infantis de Clarice Lispector os alunos refletiram sobre como foi o projeto e a descoberta da autora, agora bastante íntima de todos. O resultado dessa conversa foi a produção de cartas. Ao longo do projeto foi destacado que Clarice escrevia e recebia muitas cartas, em função de morar boa parte da sua vida fora do país. Essas comunicações a partir das cartas revelam muitos detalhes do cotidiano de Clarice e também do seu processo criativo, a preparação dos livros e o modo como ela lidava com a crítica acerca do seu trabalho. Algumas dessas questões foram compartilhadas com os alunos na aula sobre a biografia da autora. A importância dos registros dessas cartas foi amplamente abordada por Gotlib (2009a) e Moser (2017) e, recentemente, em livros que recuperam essas correspondências, a exemplo das que foram endereçadas ao escritor Fernando Sabino, amigo muito próximo a Clarice.

Ainda que essas cartas produzidas pelas crianças no projeto não pudessem ser lidas por Clarice no plano da realidade, compreende-se que o ato da escrita é precioso por fazer com que as crianças dialoguem com essa Clarice que cada um criou em sua mente, a Clarice escritora, mãe, dona de um cachorro chamado Ulisses, que "matou os peixes" dos filhos, que erra, que acerta, que inventa histórias, que faz das suas vivências as suas próprias narrativas. Que deu nomes de pessoas aos bichos. Que humanizou esses bichos para que eles ficassem mais próximos de nós. Que também afirmou ser ela um bicho, aproximando-se de uma vida mais instintiva (DINIS, 2003; MOSER, 2017).

Não foram raras as vezes que as crianças endereçaram-Ihe dúvidas sobre as suas obras e sua vida. Todos conversaram o tempo todo com essa representação muito pessoal de Clarice. O próprio nome Clarice, mencionado por muitos como muito bonito, diferente do que conheciam. Refletimos que esse processo de construção de uma intimidade entre autora e leitores e futuros escritores é fundamental na educação de nossas crianças. Ao travarem esses diálogos, ora fantasiosos, ora "quase de verdade", operaram uma aproximação com a literatura que talvez seja o ponto de partida para diversas outras incursões no futuro. 
Como conclusão do projeto, os alunos puderam experienciar a construção de um livro com a narrativa dessa imersão no universo da autoria, mediada pela obra de Clarice Lispector. Os coordenadores do projeto organizaram um livro que reunia as principais produções textuais dos alunos ao longo do projeto (SCORSOLINI-COMIN; SILVA, 2018b). Ilustrações realizadas após os encontros sobre as obras trabalhadas também compuseram o livro, que foi apresentado à comunidade em um lançamento que contou com a leitura de textos por parte dos alunos, em formato de sarau, a apresentação da biografia de Clarice Lispector por parte dos organizadores do projeto e com espaço para uma sessão de autógrafos com a presença de familiares e do corpo docente da escola. Avalia-se que a presente experiência contribuiu para propiciar ao aluno do Ensino Fundamental uma reflexão sobre a construção da autoria, do modo como o contexto e as experiências pessoais podem direcionar a escrita e de como nossas obras (bilhetes, contos, cartas, livros) não são neutras, mas prenhes de sentidos que fazem parte de nosso processo pessoal de amadurecimento e de conhecimento do mundo, aspectos estes capturados pelo fenômeno da autoria.

\section{CONSIDERAÇÕES FINAIS}

Este relato de experiência evocou a discussão acerca de como o artista - no caso, a autora Clarice, e também a criança-autora, podem apropriar-se das tensões e experiências do sujeito com a realidade e transformarem-nas em manifestação artística. Como abordado por Baiocchi e Niebielski (2009), o leitor também pode se aproximar da figura do autor - e do artista - ao construir suas próprias interpretações a partir de um livro, por exemplo, ou de uma obra de arte. Esse processo estimularia a imaginação e a criação, aproximando o leitor da figura do autor.

O planejamento deste projeto envolveu a articulação não apenas entre conteúdo específico de literatura brasileira, mas de conteúdos próprios da Psicologia, da História e da Filosofia, por exemplo. Nesse sentido, trouxemos à baila a construção de um repertório que envolveu não apenas a contação de histórias para as crianças, histórias essas produzidas nos principais livros de Clarice Lispector voltados para o público infantil, mas de possibilidade de que essas crianças entrassem em contato com conteúdos que circundam a produção literária da autora.

Essa articulação pode ser potente no desenvolvimento da criança e em sua socialização na escola, no estabelecimento dos relacionamentos interpessoais e em seu próprio processo de amadurecimento emocional. A proposta foi a de que as crianças 
pudessem ouvir essas histórias ao longo de algumas semanas e fizessem produções específicas a respeito de cada uma das obras de Clarice Lispector, refletindo sobre quais os principais aspectos veiculados na obra em termos de conteúdo, seu contexto de produção, como são os personagens, os principais enredos, bem como discussões que ultrapassam os livros e o modo como as crianças podem dialogar com os elementos trazidos nas narrativas.

Permitir o contato dos alunos com a biografia da autora é um processo essencial na compreensão de suas narrativas e dos alcances desses livros. Abordando a inequívoca ligação entre autora e obra, possibilitou-se uma aproximação mais significativa com o público-alvo, buscando ressonâncias da biografia da autora nos seus livros e na emergência do seu itinerário criativo. Incentivar a reflexão sobre as relações entre autor e obra foi um processo fortalecido com os alunos do projeto, facilitando o percurso interpretativo e a apropriação dos enredos por parte dos jovens leitores - e escritores - em formação.

Por fim, este estudo trouxe à baila não apenas leitores em potencial da obra dessa importante escritora, mas também ávidos escritores em busca de espaços para o compartilhamento de experiências, ideias, fantasias e explicações sobre o mundo e as relações estabelecidas entre pessoas, animais, conhecimentos e sentimentos. Ao veremse como escritores, esses alunos de agora retomam a própria biografia da autora em suas vivências infantis, encontrando na escrita um veículo não apenas de expressão de sensações e experiências, mas também de significação e de existência no mundo.

Retomando o título do presente estudo, inspirado nas recomendações de Clarice para a escrita infantil, pode-se compreender que a proposta interventiva aqui narrada privilegiou não apenas a escrita das sensações, mas o contato dessas crianças com esses elementos no processo de autoria, o que não ocorre descolado do amadurecimento emocional corporificado na infância. Para tornar-se autor, desse modo, Clarice recomenda que a criança aprenda não a narrar fatos, mas as próprias experiências. Para essa narrativa, é mister que o autor ultrapasse o seu lugar de observador de um mundo de modo distanciado, mas que possa, essencialmente, experienciar esse mundo, corporificando-o.

\section{REFERÊNCIAS}

BAIOCCHI, A.; NIEBIELSKI, D. Psicologia e Literatura: um diálogo possível. Travessias, v. 3, n. 3, p. 153-160, 2009.

BAKHTIN, M. M. Estética da criação verbal. (5aㅡ ed. Trad. P. Bezerra). São Paulo: Martins Fontes, 2010. 
DINIS, N. F. Pedagogia e literatura: crianças e bichos na literatura infantil de Clarice Lispector. Educar, Curitiba, v. 21, p. 271-286, 2003.

FERREIRA, T. M. Eu sou uma pergunta: uma biografia de Clarice Lispector. Rio de Janeiro: Rocco, 1999.

GOTLIB, N. B. Clarice: uma vida que se conta. (6- ed. rev. aum.). São Paulo: Editora da Universidade de São Paulo, 2009 (a).

GOTLIB, N. B. Clarice fotobiografia. (2 $2^{\mathrm{a}}$ ed.). São Paulo: Editora da Universidade de São Paulo e Imprensa Oficial do Estado de São Paulo, 2009 (b).

LISPECTOR, C. Felicidade clandestina. Rio de Janeiro: Rocco, 1998.

LISPECTOR, C. A mulher que matou os peixes. Rio de Janeiro: Rocco, 1999 (a).

LISPECTOR, C. Quase de verdade. Rio de Janeiro: Rocco, 1999 (b).

LISPECTOR, C. A vida íntima de Laura. Rio de Janeiro: Rocco, 1999 (c).

LISPECTOR, C. Aprendendo a viver. Rio de Janeiro: Rocco, 2004.

LISPECTOR, C. O mistério do coelho pensante e outros contos. Rio de Janeiro: Rocco, 2010.

MOSER, B. Clarice, Trad. J. G. Couto. São Paulo: Companhia das Letras, 2017.

POJAR, G. B.; SCORSOLINI-COMIN, F. Um corpo que arde: corporeidade e produção de subjetividade em Clarice Lispector. Subjetividades, Fortaleza, v. 20, n. 1, e7365, 2020.

SCORSOLINI-COMIN, F. Família, sujeito composto: conjugalidade dos pais e sua relação com o bem-estar subjetivo e a satisfação nos relacionamentos amorosos dos filhos. Tese (Doutorado em Psicologia) - Faculdade de Filosofia, Ciências e Letras de Ribeirão Preto, Universidade de São Paulo. Ribeirão Preto, 2012.

SCORSOLINI-COMIN, F. A infância clandestina em Clarice Lispector. Revista do SELL, Uberaba, v. 8, n. 2, p. 185-203, 2019.

SCORSOLINI-COMIN, F.; SANTOS, M. A. Todos passam pela via crucis: a corporeidade em Clarice Lispector. Psicologia em Estudo, Maringá, v. 15, n. 3, p. 623-632, 2010.

SCORSOLINI-COMIN, F.; SILVA, A. A. "Por que só no fim do livro?": revisitando a grupalidade com crianças. Revista da SPAGESP, Ribeirão Preto, v. 19, n. 2, p. 1-6, 2018 (a).

SCORSOLINI-COMIN, F.; SILVA, A. A. A mulher que salvou os peixes: Clarice Lispector e o universo infantil. Ribeirão Preto, SP: INEPAD, 2018 (b).

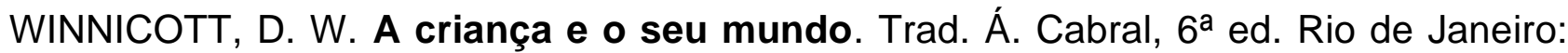
LTC, 2017. 
SCORSOLINI-COMIN, F.

Como citar este artigo (ABNT)

SCORSOLINI-COMIN, F. Suprimir os fatos e privilegiar as sensações: a emergência da criança-autora em Clarice Lispector. Revista do SELL, Uberaba, MG, v. 10, n. 01, p. 135154, 2021. Disponível em: <inserir link de acesso>. Acesso em: inserir dia, mês e ano de acesso. DOI: inserir link do DOI.

Como citar este artigo (APA)

Scorsolini-Comin, F. (2021) Suprimir os fatos e privilegiar as sensações: a emergência da criança-autora em Clarice Lispector. Revista do SELL, 10 (1), 135-154. DOI: inserir link completo de acesso ao DOI. 